\title{
Improved Theory on the Rate of Reduction of Single Particles and Fixed Beds of Iron Oxide Pellets with Hydrogen*
}

\author{
By Munekazu OHMI** and Tateo USUI**
}

\begin{abstract}
Syonpsis
Single hematite pellets having not so large porosity are reduced over a temperature range $600 \sim 1000^{\circ} \mathrm{C}$ and a flow-rate range $0.1 \sim 20 \mathrm{Nl} / \mathrm{min}$. In the initial stage of reduction, hydrogen is diluted by nitrogen which flows through a reactor until it reaches a set temperature, and the reaction retards especially at low flow rates. In the course of reduction, hydrogen is also diluted by the product gas. For these dilution processes, the dispersion model is introduced into the unreacted-core shrinking (UCS) models for one and three interfaces in consideration of the resistance due to the rate of gas flow proposed by Clair. With appropriate selection of kinetic constants, the modified models produce greatly improved fit to experimental data.

Porous wïstite pellets are reduced and their reduction rates are analyzed by using modified grain and intermediate models; for this case the latter analysis gives rather satisfactory results. Then, multi-stage diffusional $(M S D)$ model is derived on the basis of the intermediate model, and the calculated results are compared with hematite-reduction data. Both reduction curves based on this model and the three interface UCS model reproduce experimental ones very well, while interface radii based on the MSD model simulate cross-sectional view much better than those based on the three interface model. When basic hematite pellets are reduced at $1000^{\circ} \mathrm{C}$, the reduction rate decreases extremely in the final stage. An equation of solidstate diffusion is introduced into the MSD model; fairly good agreement is seen up to the final stage.

Packed beds of Hamersley pellets are reduced over a temperature range $600 \sim 1000^{\circ} \mathrm{C}$ and a flow-rate range $1 \sim 45 \mathrm{Nl} / \mathrm{min}$. Not only reduction curves and exit hydrogen flow-rate but core radii and local fractionalreduction in beds reduced partially are measured. The equations of mass balance for a fixed bed are combined with the UCS models for one and three interfaces and numerical calculations are done by the method of characteristics or by an approximate approach; the results calculated by both methods are much the same. Calculated results based on the three interface model reproduce experimental data much better than those based on the Rist model or the one interface model.

Porous pure-hematite pellets and basic pellets (fluxed pellets) are reduced at 800 and $1000^{\circ} \mathrm{C}$, respectively, and their rates are analyzed by the approximate approach based on the MSD models with and without the solidstate diffusion; each analysis reproduces respective experimental data very well.
\end{abstract}

\section{Introduction}

The unreacted-core shrinking (UCS) models for on $\mathrm{e}^{1-9)}$ or three ${ }^{10-12)}$ interfaces and diffusional models $^{13-22)}$ such as the intermediate model ${ }^{13)}$ or the grain models ${ }^{14,15)}$ have been examined in order to analyze the reduction process of iron oxide pellets. For iron oxide pellets having not so large porosity, the reduction proceeds topochemically in a macroscopic sense, so that the analyses based on the UCS models can approximately reproduce experimental data. For porous pellets, however, the UCS models do not give a detailed feature of the reduction rigorously because the reaction zone, in which chemical reaction and gaseous diffusion would proceed simultaneously, was observed microscopically.

The present report covers those analyses based on the UCS models and diffusional models which are applied to the rate of reduction of single particles and fixed beds of iron oxide pellets with hydrogen and are carried out by the present authors and co-workers.

\section{Rate of Reduction of Single Iron Oxide Pellets}

1. Analyses Based on the Unreacted-core Shrinking (UCS) Models

1. Theoretical Study on the Resistance Due to the Rate of Gas Flow ${ }^{8)}$

The one interface UCS model for isothermal system has been approximately applied to analyses of reduction of pellets having a few steps of reaction as well as a single step reaction. ${ }^{4,9,23)}$ Many investigators have shown that the overall reduction process should be described as being under a mixed control of intra-particle diffusion, chemical reaction and flow rate. Nowadays, there are two sorts of analyses for the influence of flow rate; in the one analysis ${ }^{1-5)}$ only the contribution of mass-transfer resistance in a gas film is taken into account, and the other ${ }^{6-9,23)}$ which was proposed by Clair includes the contribution of both the mass-transfer resistance and the resistance due to the rate of gas flow. The latter is examined theoretically as follows:

(1) Theory

When the reduction of a single hematite pellet proceeds in accordance with the one interface model, the rates of hydrogen diffusion through the gas film, of gaseous diffusion through the shell of reduced iron, and of chemical reaction at the interface are respectively written as

$$
\begin{aligned}
& n_{\mathrm{H}_{2} \mathrm{f}}=-4 \pi r_{0}^{2} k_{\mathrm{f}}\left(C_{\mathrm{H}_{2} \mathrm{a}}-C_{\mathrm{H}_{2}(0)}\right), \ldots \ldots \ldots \ldots \ldots \ldots \\
& n_{\mathrm{H}_{2} \mathrm{~d}}=-4 \pi D_{\mathrm{e}}\left(C_{\mathrm{H}_{2}(0)}-C_{\mathrm{H}_{2} \mathrm{i}}\right) /\left(1 / r_{\mathrm{i}}-1 / r_{\mathrm{o}}\right), \\
& n_{\mathrm{H}_{2} \mathrm{c}}=-4 \pi r_{\mathrm{i}}^{2} k_{\mathrm{c}}(1+1 / K)\left(C_{\mathrm{H}_{2} \mathrm{i}}-C_{\mathrm{H}_{2} \mathrm{e}}\right) \ldots \ldots \ldots . . .
\end{aligned}
$$

Under a quasi-steady state, the reduction proceeds as follows:

$$
n_{\mathrm{H}_{2} \mathrm{P}}=n_{\mathrm{H}_{2} \mathrm{~d}}=n_{\mathrm{H}_{2} \mathrm{c}} \equiv n_{\mathrm{H}_{2}}(<0) .
$$

The average concentration of hydrogen around the pellet will be somewhat similar to that of the gas discharged from the reactor, i.e.,

$$
C_{\mathrm{H}_{2} \mathrm{a}}=C_{\mathrm{H}_{2} \mathrm{~b}}+\kappa n_{\mathrm{H}_{2}} / V_{\mathrm{T}} \cdot \quad(0 \leqq \kappa \leqq 1)
$$

This means that some sort of flow resistance exists

* Partly published in Bulletin of The Japan Institute of Metals, 19 (1980), 23, in Japanese. English version received September 3, 1980.

** Department of Metallurgical Engineering, Faculty of Engineering, Osaka University, Yamadaoka, Suita 565. 
between the bulk gas and the gas around the pellet. The resistance due to the rate of gas flow per surface area of a pellet may be given as $4 \pi r_{\mathrm{o}}^{2} / V_{\mathrm{T}}$ and $\kappa$ indicates the contribution of the resistance.

From Eqs. (1) (5), the overall reduction rate can be expressed as follows:

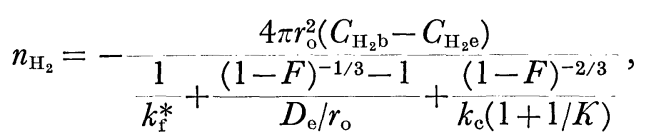

in which,

$$
\begin{aligned}
k_{\mathrm{f}}^{*} & =\left(1 / k_{\mathrm{f}}+4 \pi \kappa r_{\mathrm{o}}^{2} / V_{\mathrm{T}}\right)^{-1}, \\
F & =1-\left(r_{\mathrm{i}} / r_{\mathrm{o}}\right)^{3} \cdot \ldots \ldots \ldots \ldots \ldots
\end{aligned}
$$

Combination of the relation

$$
n_{\mathrm{H}_{2}}=(4 / 3) \pi \rho_{\mathrm{O}}^{(\mathrm{h})} d r_{\mathrm{i}}^{3} / d t=-(4 / 3) \pi r_{\mathrm{o}}^{3} \rho_{\mathrm{O}}^{(\mathrm{h})} d F / d t .
$$

and Eq. (6) yields the relation between $F$ and $t$ after integration, i.e.,

$$
\begin{aligned}
& \frac{1}{\rho_{\mathrm{O}}^{(\mathrm{h})} r_{\mathrm{o}}} \int_{0}^{t}\left(C_{\mathrm{H}_{2} \mathrm{~b}}-C_{\mathrm{H}_{2} \mathrm{e}}\right) d t=\frac{F}{3 k_{\mathrm{f}}^{*}} \\
& +\frac{3-3(1-F)^{2 / 3}-2 F}{6 D_{\mathrm{e}} / r_{\mathrm{o}}}+\frac{1-(1-F)^{1 / 3}}{k_{\mathrm{c}}(1+1 / K)} .
\end{aligned}
$$

This can be rewritten as $^{3)}$

$$
\begin{aligned}
& \Psi(t) \equiv \frac{1}{\tilde{F}}\left\{\frac{1}{\rho_{\mathrm{O}}^{(\mathrm{h})} r_{\mathrm{o}}} \int_{0}^{t}\left(C_{\mathrm{H}_{2} \mathrm{~b}}-C_{\mathrm{H}_{2} \mathrm{e}}\right) d t-\frac{F}{3 k_{\mathrm{f}}^{*}}\right\} \\
& =\frac{3 \tilde{F}-2 \tilde{F}^{2}}{6 D_{\mathrm{e}} / r_{\mathrm{o}}}+\frac{1}{k_{\mathrm{c}}(1+1 / K)},
\end{aligned}
$$

where,

$$
\tilde{F}=1-(1-F)^{1 / 3} \text {. }
$$

The integration term in Eqs. (10) and (11) remains as it is, because $C_{\mathrm{H}_{2} \mathrm{~b}}$ is time-variant in some cases.

(2) Results and Discussion

Figure 1 shows variations of the overall reductionrate with the overall fractional-reduction for the cases with $(\kappa=1)$ and without $(\kappa=0)$ the resistance pro-

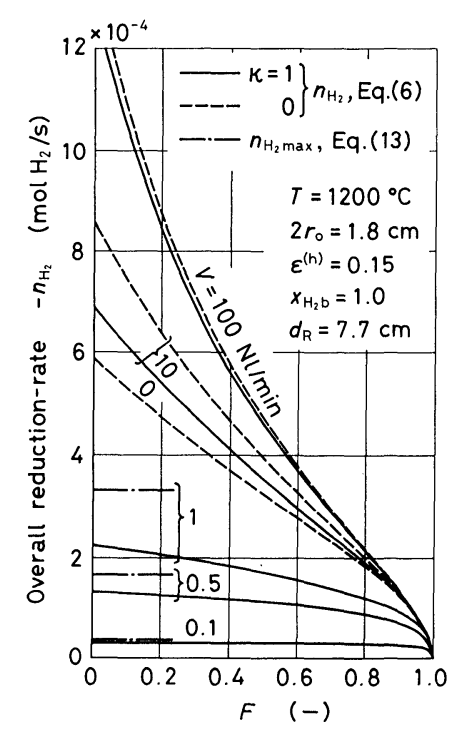

Fig. 1. Dependence of overall reduction-rate on flow rate. (One interface model) posed by Clair. ${ }^{6}$ ) The overall reduction-rate in the case where the utilization of gas is $100 \%$ is defined by

$$
\begin{aligned}
n_{\mathrm{H}_{2} \max } & =-x_{\mathrm{H}_{2} \mathrm{~b}} V /\{22.4 \times 60(1+1 / K)\} \\
& =-V_{\mathrm{T}}\left(C_{\mathrm{H}_{2} \mathrm{~b}}-C_{\mathrm{H}_{2} \mathrm{e}}\right) \ldots \ldots \ldots \ldots \ldots \ldots
\end{aligned}
$$

and shown in Fig. 1. It coincides with Eq. (6) when the reduction is controlled only by the resistance proposed by Clair. Because there is only a slight difference between the values of $k_{\mathrm{f}}^{*}$ for $\kappa=0$ and 1 at high flow rates, two overall reduction-rates with $\kappa=0$ and 1 coincide fairly well. As the flow rate decreases, the reduction rate with $r=1$ decreases in such a way as the value in the initial stage of reduction approaches gradually to $n_{\mathrm{H}_{2} \text { max }}$. However the reduction rate with $\kappa=0$ slightly decreases, and finally it leads to such a consequence that the amount of hydrogen consumed is more than that supplied.

\section{Experimental Study on the Resistance due to the Rate} of Gas Flow ${ }^{24,25,48)}$

As theoretically shown in the preceding section, the analysis with the resistance proposed by Clair is better than the one without it at low flow rates. However, at extremely low flow rates, experimental data could not be simulated even by the former analysis. ${ }^{23,26)}$ The resistance is examined experimentally as follows:

(1) Experimental

Basic pellets $\left(\mathrm{SiO}_{2}: 0.75 \mathrm{wt} \%, \mathrm{Al}_{2} \mathrm{O}_{3}: 0.33 \mathrm{wt} \%\right.$, $\left.\mathrm{CaO}: 1.62 \mathrm{wt}^{\mathrm{t}} \%, \varepsilon^{(\mathrm{h})}=0.24,2 r_{\mathrm{o}}=1.1 \mathrm{~cm}\right)$ were reduced in two reactors of 54 and $156 \mathrm{~mm}$ I.D. over a temperature range 600 to $1000^{\circ} \mathrm{C}$ and a flow-rate range 0.1 to $20 \mathrm{~N} l / \mathrm{min}$. After passing through a packed bed of alumina balls for preheating and rectifying and through an entrance region, flow may form parabolic velocity-distribution near the pellet. On the other hand, the concentration around the pellet may depend on the mixing conditions, such as the velocity distribution around the pellet, the temperature gradient and natural convection in a reactor. And the resultant mixing condition will be the one between the backmix flow (corresponds to $\kappa=1$ ) and plug flow (corresponds to $\kappa=0$ ).

Fractional reduction was evaluated from the loss in weight of a pellet. Cross-sections of partially reduced pellets were observed and radial positions of their reaction interfaces were measured.

(2) Results and Discussion

Figure 2 shows the mixed-control plots: $\Psi(t)$ of Eq. (11) vs. $3 \tilde{F}-2 \tilde{F}^{2}$ with and without the resistance due to the rate of gas flow. At high flow rates, two sorts of plots in the middle stage of reduction are on much the same straight line, which gives the same values of $k_{\mathrm{c}}$ and $D_{\mathrm{e}}$. The difference between the two increases as flow rate decreases, and $k_{\mathrm{c}}$ and $D_{\mathrm{e}}$ cannot be determined.

Then, the variation of mixed-control plots with $\kappa$ at $0.2 \mathrm{Nl} / \mathrm{min}$ as an example is illustrated in a figure ${ }^{48)}$ to examine the contribution of the resistance. The same pellet should have the same values of $k_{\mathrm{e}}$ and $D_{\mathrm{e}}$ irrespective of flow rate. Judging from this viewpoint, comparison of such a figure ${ }^{48)}$ with Fig. 2 gives the optimum value $\kappa \fallingdotseq 0.8$. Therefore, the resistance 


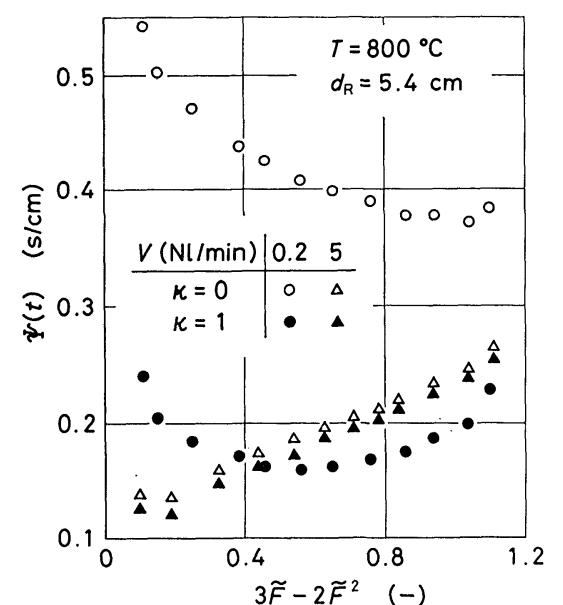

Fig. 2. Effect of flow rate on the mixed-control plots. $\left(C_{\mathrm{H}_{2} \mathrm{~b}}=\right.$ const. $)$

proposed by Clair should be taken into account to some extent at low flow rates.

\section{Analysis Considering Initial Variation of Gas Concen-} tration $^{25,27,28,48)}$

At low flow rates discussed above, a slow reaction rate was observed in the initial stage of reduction, which had been considered by other investigators ${ }^{29}$ ) to be caused by nucleation. However, because the reducing gas might be diluted by an inert gas $\left(\mathrm{N}_{2}\right)$ which flowed through a reactor until it reached a set temperature, such a retardation could be also induced by the dilution process. Here, the dispersion model ${ }^{30}$ ) is introduced into the UCS models for one and three interfaces and calculated results are compared with experimental data.

(1) Time-variant Concentration of Hydrogen in Bulk Phase

Dilution process by nitrogen at the beginning of reduction will be described by the dispersion model of closed-open (semi-infinite) system for a perfect step input. ${ }^{30)}$ When hydrogen begins to flow into an inlet cock in front of the reactor at $t=0$, its concentration in the bulk phase $C_{\mathrm{H}_{2} \mathrm{~b}}$ is given by

$$
\begin{aligned}
C_{\mathrm{H}_{2} \mathrm{~b}}= & C_{\mathrm{H}_{2} \mathrm{~b}^{\circ}}\{\exp (P e) \operatorname{erfc}(\sqrt{P e / \zeta} / 2+\sqrt{P e \zeta} / 2) \\
& +\operatorname{erfc}(\sqrt{P e / \zeta} / 2-\sqrt{P e \zeta / 2})\} / 2, \ldots \ldots \ldots .
\end{aligned}
$$

where,

$$
\zeta=t / \xi, \quad \xi=L / u_{\mathrm{m}}, \quad P e=u_{\mathrm{m}} L / D,
$$

$C_{\mathrm{H}_{2} \mathrm{~b}^{\circ}}$ : hydrogen concentration in bulk phase (time-invariant).

(2) Results and Discussion

Figure 3 shows the mixed-control plots with and without Eq. (14) at $\kappa=0.8$. The former plots agree better with the plots at high flow rates (see Fig. 2) in the middle stage than the latter. As shown in Fig. 4, the reduction curves calculated by the use of Eq. (14) fit fairly well to experimental data.

Figure 5 shows comparison of calculated reactioninterfaces with experimental data. Much the same results were obtained in the case of acid pellets. Kinetic expressions based on the three interface model were given in Ref. 10) or 11). Six parameters (three

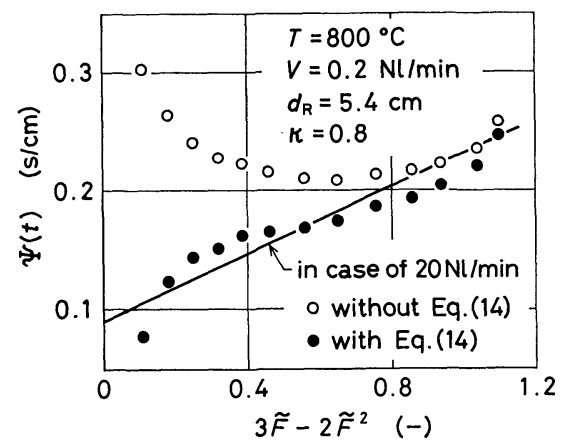

Fig. 3. Comparison between the mixed-control plots with and without Eq. (14).

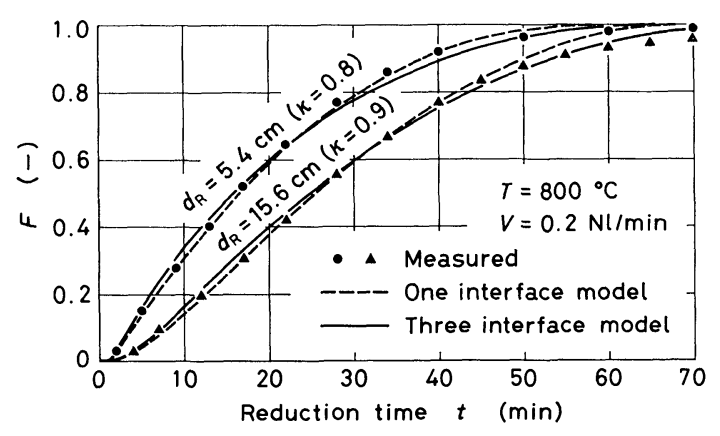

Fig. 4. Comparison between measured and calculated reduction curves; the optimum values of $\kappa$ have been determined in Ref. 48).

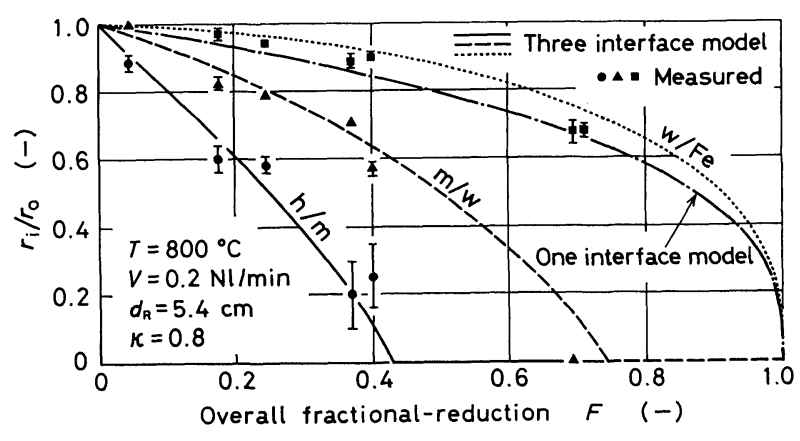

h: hematite, $\mathrm{m}$ : magnetite, $\mathrm{w}$ : wüstite

Fig. 5. Variation of core radii with overall fractional-reduction.

$k_{\mathrm{c}}$ for three interfaces and three $D_{\mathrm{e}}$ for three layers) were so determined by trial and error that calculated curves of both Figs. 4 and 5 might agree with respective experimental data as much as possible, while Murayama et al. ${ }^{9)}$ determined them by a step-wise reduction technique.

\section{Analyses Based on the Diffusional Models}

1. Analysis Based on the One-stage Diffusional Mode ${ }^{31)}$

The basic equations given by Szekely and Evans ${ }^{14}$ ) and $\mathrm{Hara}^{15)}$ for the grain model were modified and numerical computation was carried out for wüstite reduction.

\section{(1) Theory}

Because constituent particles in a pellet are very small, the gaseous diffusion through the particles is 
considered to be negligible. The reduction of the particles is, therefore, thought to be controlled by the chemical reaction in a topochemical fashion. Then, the basic equations relating $f$ and $C_{\mathrm{H}_{2}}$ to $t$ and $r$ are

$$
\begin{aligned}
& \frac{\partial\left(\varepsilon C_{\mathrm{H}_{2}}\right)}{\partial t}= \frac{1}{r^{2}} \frac{\partial}{\partial r}\left(r^{2} D_{\mathrm{e}} \frac{\partial C_{\mathrm{H}_{2}}}{\partial r}\right)-\frac{3\left(1-\varepsilon^{(\mathrm{w})}\right) k_{\mathrm{c}}}{r_{\mathrm{c}}} \\
& \times\left(1+\frac{1}{K}\right)(1-f)^{2 / 3}\left(C_{\mathrm{H}_{2}}-C_{\mathrm{H}_{2} \mathrm{e}}\right), \\
& \frac{\partial f}{\partial t}=\frac{3 k_{\mathrm{c}}}{\rho_{\mathrm{O}}^{(\mathrm{w})} r_{\mathrm{c}}}\left(1+\frac{1}{K}\right)(1-f)^{2 / 3}\left(C_{\mathrm{H}_{2}}-C_{\mathrm{H}_{2} \mathrm{e}}\right) .
\end{aligned}
$$

The initial and boundary conditions are

$$
\begin{aligned}
& t=0, r<r_{\mathrm{o}}: f=0, C_{\mathrm{H}_{2}}=C_{\mathrm{H}_{2} \mathrm{e}}, \\
& t \geqq 0, r=0: \quad \partial f / \partial r=0, \partial C_{\mathrm{H}_{2}} / \partial r=0 \text {, } \\
& t \geqq 0, r=r_{\mathrm{o}}: f=1, D_{\mathrm{e}} \partial C_{\mathrm{H}_{2}} / \partial r=k_{\mathrm{f}}^{*}\left(C_{\mathrm{H}_{2} \mathrm{~b}}-C_{\mathrm{H}_{2}(0)}\right) \text {. }
\end{aligned}
$$

Here, $k_{\mathrm{c}}$ is evaluated from an expression ${ }^{32)}$ obtained experimentally by using wüstite plates and $D_{\text {e }}$ from the following expression ${ }^{33)}$ taken into account the effects of dilution gas $\left(\mathrm{N}_{2}\right)$ and Knudsen diffusion:

$$
\begin{aligned}
D_{\mathrm{\theta}}= & \left(\varepsilon^{2} / \tau\right) /\left[1 / D_{\mathrm{H}_{2}-\mathrm{H}_{2} \mathrm{O}}+1 / D_{K, \mathrm{H}_{2}}\right. \\
& \left.-\left(1 / D_{\mathrm{H}_{2}-\mathrm{H}_{2} \mathrm{O}}-1 / D_{\mathrm{H}_{2}-\mathrm{N}_{2}}\right) x_{\mathrm{N}_{2} \mathrm{~b}}\right],
\end{aligned}
$$

where $\tau$ denotes tortuosity factor. By using these equations, $f$ and $C_{\mathrm{H}_{2}}$ are calculated numerically.

(2) Results and Discussion

Calculated results were examined as compared with the experimental data reported previously by Takahashi et al. ${ }^{4)}$ about the reduction of porous wüstite pellets with $\mathrm{H}_{2}-\mathrm{N}_{2}$ mixture. Figure 6 exemplifies distribution profiles of local fractional-reduction and hydrogen concentration in a pellet. As the reduction proceeds, the former profile moves with almost the same form, and such a behavior is independent of temperature. When the reaction zone is defined as the region of $0.1 \leqq f \leqq 0.9$, the width $\Delta r$ is given from this figure as $\Delta r / r_{\mathrm{o}} \fallingdotseq 0.065$, which is much the same as the measured value 0.05 by Takahashi $e t$ al. Mixed-control plots of the calculated reductioncurves form the curves bending both ends upward, as is seen in experimental ones given by Takahashi et al. From these two facts, the present model is considered to represent the reduction behavior of porous wüstite pellets fairly well.

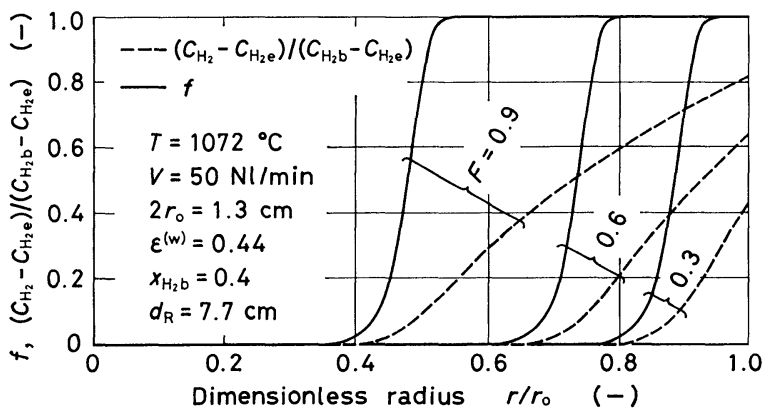

Fig. 6. Distribution profiles of local fractional-reduction and hydrogen concentration in a pellet. (Grain model)

\section{Experimental Study on the Reduction Rate of Porous Wüstite Pellets ${ }^{34}$}

Porous wüstite pellets were reduced and their reduction rates were analyzed by using the modified grain $^{31)}$ and intermediate ${ }^{13)}$ models.

(1) Experimental

A hematite pellet was pre-reduced to wüstite with $\mathrm{H}_{2}-\mathrm{H}_{2} \mathrm{O}$ mixture of a set concentration which was supplied from a water-vapor saturator. Successively, this wüstite pellet was reduced to iron with hydrogen and its reduction curve was determined by measuring the loss in its weight (see Fig. 1 in Ref. 34)). Radial position of a reaction zone was measured by observing or EPMA-analyzing the cross section of a pellet reduced partially.

(2) Results and Discussion

Calculated and measured reaction-zones in terms of its radial position as a function of $F$ agree fairly well except in the initial stage of reduction (see Fig. 2 in Ref. 34)); in this stage reduced iron nuclei disperse all over the pellet. In the course of reduction, wüstite remains in the central part of relatively large particles because of their low rate of reduction (see Photo. 1 in Ref. 34)). Apart from these phenomena, it is confirmed also from another figures such as reduction curves and distribution profiles of local fractional-reduction measured with EPMA (see Fig. 7) that diffusional models reproduce the experimental data fairly well. Figure 7 and the other figures show that the analysis based on the intermediate model gives rather satisfactory results.

\section{Analysis Based on the Multi-stage Diffusional (MSD) Model $^{35)}$}

When the gaseous reduction of a porous hematite pellet proceeds topochemically in a macroscopic sense, the process can be reproduced approximately in some cases by the analyses based on the UCS models. Even in such cases, however, each apparent reaction-interface forms a reaction zone in a microscopic view. Here, multi-stage diffusional (MSD) model is derived on the basis of the intermediate model, ${ }^{13}$ ) and the calculated results are compared with experimental data using the basic pellets (see Section II. 1.2).

(1) Theory

Quasi-steady state is assumed, and then the equations of mass balance for the 1 st $\left(0 \leqq r \leqq r_{1}, \mathrm{~h}+\mathrm{m}\right)$, the

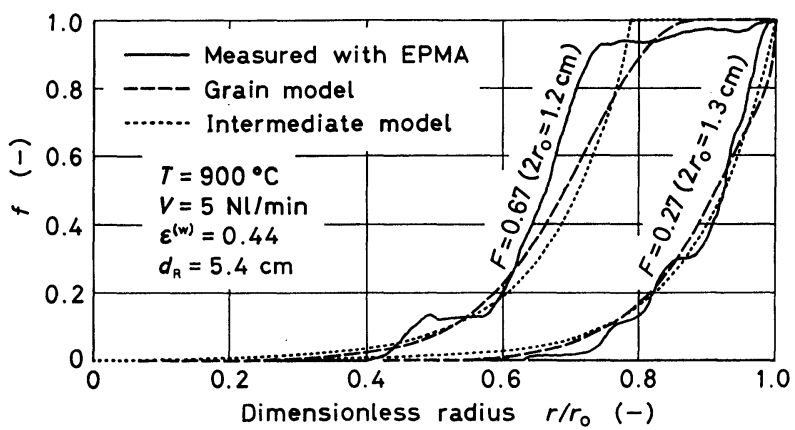

Fig. 7. Comparison between measured and calculated distribution profiles of local fractional-reduction in pure hematite pellets. 
2nd $\left(r_{1}<r \leqq r_{2}, \mathrm{~m}+\mathrm{w}\right)$, the $3 \mathrm{rd}\left(r_{2}<r \leqq r_{3}, \mathrm{w}+\mathrm{Fe}\right)$, and the 4 th $\left(r_{3}<r \leqq r_{0}, \mathrm{Fe}\right)$ zones are

$$
\begin{gathered}
0=\left(D e^{(j)} / r^{2}\right) d\left(r^{2} d C_{\mathrm{H}_{2}}^{(j)} / d r\right) / d r \\
-k_{\mathrm{v}}^{(j)}\left(\rho_{\mathrm{O}}^{(s)}-\rho_{\mathrm{O}}^{(t)}\right)\left(C_{\mathrm{H}_{2}}^{(j)}-C_{\mathrm{H}_{2} \mathrm{e}}^{(t)}\right), \ldots \ldots \ldots . .(22) \\
\partial \rho_{\mathrm{O}}^{(j)} / \partial t=-k_{\mathrm{v}}^{(j)}\left(\rho_{\mathrm{O}}^{(s)}-\rho_{\mathrm{O}}^{(t)}\right)\left(C_{\mathrm{H}_{2}}^{(j)}-C_{\mathrm{H}_{2} \mathrm{e}}^{(t)}\right) . \ldots \ldots(2) \\
(j, s, t)=(1, \mathrm{~h}, \mathrm{~m}),(2, \mathrm{~m}, \mathrm{w}),(3, \mathrm{w}, \mathrm{Fe}),(4, \mathrm{Fe}, \mathrm{Fe})
\end{gathered}
$$

Boundary conditions are

$$
\begin{aligned}
& r=0: \quad d C_{\mathrm{H}_{2}}^{(1)} / d r=0, \\
& r=r_{\mathrm{j}}: \quad D_{e}^{(j)} d C_{\mathrm{H}_{2}}^{(j)} / d r=D_{e}^{(j+1)} d C_{\mathrm{H}_{2}}^{(j+1)} / d r, \\
& \left.\begin{array}{c}
C_{\mathrm{H}_{2}}^{(j)}=C_{\mathrm{H}_{2}}^{(j+1)}, \rho_{\mathrm{O}}^{(j)}=\rho_{\mathrm{O}}^{(j+1)}=\rho_{\mathrm{O}}^{(t)}, \\
(j=1,2,3)
\end{array}\right\} \ldots \\
& r=r_{\mathrm{o}}: \quad D_{e}^{(4)} d C_{\mathrm{H}_{2}}^{(4)} / d r=k_{\mathrm{f}}^{*}\left(C_{\mathrm{H}_{2} \mathrm{~b}}-C_{\mathrm{H}_{2}(0)}\right) .
\end{aligned}
$$

By using these equations, semi-analytical relations to $C_{\mathrm{H}_{2}}$ and $\rho_{\mathrm{O}}$ are derived and then calculated numerically.

(2) Results and Discussion

Figure 8 shows calculated results based on the MSD model and the three interface model. Kinetic parameters in the MSD model were also determined by trial and error so that calculated reduction-curves and interface-radii might agree with respective experimental data as much as possible. Both calculated reduction-curves reproduce experimental ones very well, while calculated boundary-radii based on the MSD model simulate cross-sectional view much better than those based on the three interface model.

\section{Analysis Based on the Multi-stage Diffusional Model with Solid-state Diffusion ${ }^{36)}$}

When the basic hematite pellets shown in Section II. 1.2 were reduced at $1000^{\circ} \mathrm{C}$, the rate of reduction decreased extremely at the final stage. Previous analyses could not describe such a phenomena. It is observed in the course of reduction that phases of hematite, magnetite, wüstite, and iron coexist and reaction zones are formed as shown in Fig. 9. Wüstite particles are dotted with iron nuclei in the 3rd zone, but surrounded with dense iron layer in the 4th. The rate of reduction of the latter wüstite particles is con-

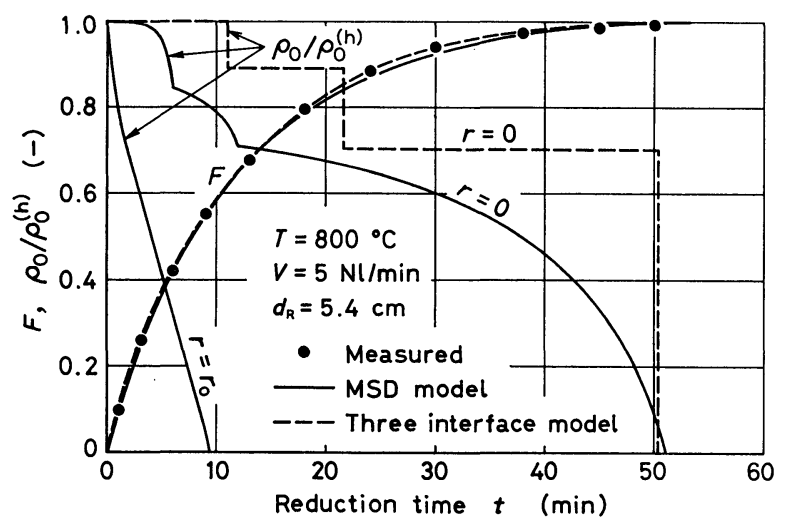

Fig. 8. Reduction curve and variation of oxygen density with time. sidered to be controlled by the rate of diffusion of oxygen ions through the recrystallizing-iron layer. ${ }^{37)}$ Here, an equation of solid-state diffusion ${ }^{38)}$ is introduced into the MSD model and the calculated results are compared with experimental data.

\section{(1) Analysis}

In the MSD model, the following further assumptions are made:

(1) In the 4th zone, the rate of reduction of the wüstite particles is given by ${ }^{38}$ )

$$
d f^{(\mathrm{w})} / d t=\left(3 k / r_{\mathrm{c}}^{2}\right) /\left\{\left(1-f^{(\mathrm{w})}\right)^{-1 / 3}-\left(1-\sigma f^{(\mathrm{w})}\right)^{-1 / 3}\right\},
$$

where,

$$
\begin{aligned}
& k=\left(D_{\mathrm{O}} C_{\mathrm{O}}^{*} / d_{\mathrm{O}}\right) V_{\mathrm{M}}(\mathrm{FeO}) / V_{\mathrm{M}}(\mathrm{Fe}) \\
& \sigma=1-V_{\mathrm{M}}(\mathrm{Fe}) / V_{\mathrm{M}}(\mathrm{FeO}), \ldots \ldots \ldots
\end{aligned}
$$

$f^{(w)}$ : fractional reduction of wüstite particle, and shrinkage of the particle diameter is considered.

(2) Because the reduction of these wüstite particles proceeded very slowly, the reaction term in the equation of molar balance of hydrogen for the 4th zone is negligible.

(3) It was found from a microscopic observation that the fractional reduction of wüstite particles at the boundary $r=r_{\mathbf{3}}$ (see Fig. 9) was nearly equal to $40 \%$. The oxygen concentration of these particles is, therefore, written as $0.6 \rho_{\mathrm{o}}^{(\mathrm{w})}$.

Under these assumptions, the fundamental equations and the boundary conditions given in the last section are partly modified and coupled with Eq. (27). (2) Results

Figures 10 and 11 show comparisons of the calculated curves with experimental data. Fairly good agreement is seen up to the final stage of reduction. Moreover, the values of $D_{0} C_{0}^{*}$ agree well with those of Kohl and Engell. ${ }^{37)}$

Various hematite pellets having several compositions and amounts of slag were made under some firing temperatures, and conditions for extreme decrease of reduction rate in the final stage were examined: The results are shown in Ref. 39).

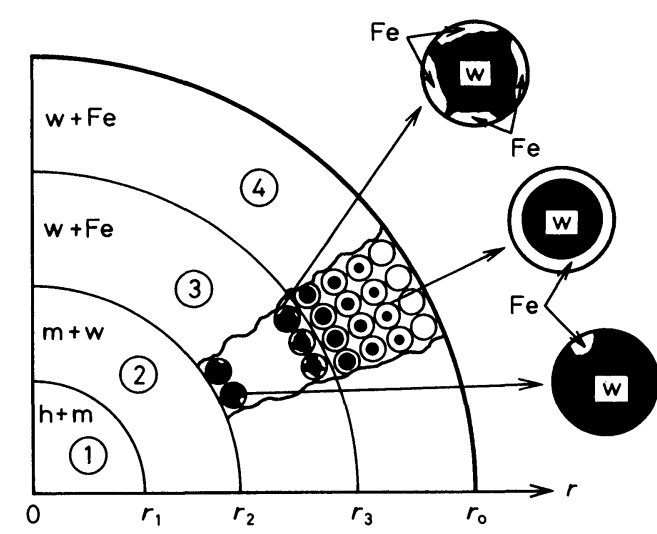

h: hematite, m: magnetite, w: wüstite

Fig. 9. Schematic representation of the MSD model with solid-state diffusion. 


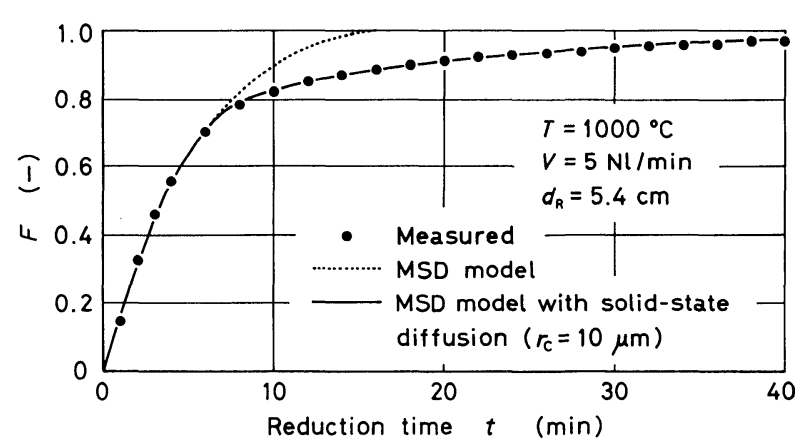

Fig. 10. Comparison of calculated reduction curves with experimental data.

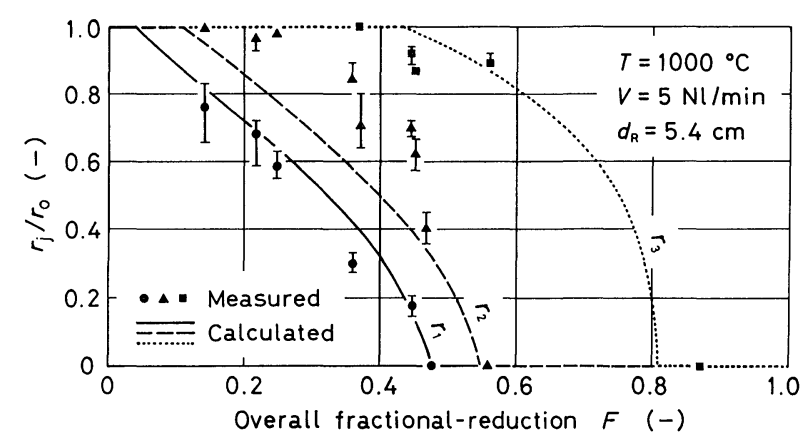

Fig. 11. Variation of boundary radii with overall fractional-reduction. (MSD model with solid-state diffusion)

\section{Rate of Reduction of Fixed Beds of Iron Oxide Pellets}

1. Analyses Based on the Unreacted-core Shrinking Models

1. Theoretical Investigation ${ }^{40}$

Reduction rate of fixed beds was analyzed by the method of characteristics and an approximate approach on the basis of the UCS models for one and three interfaces. An analysis based on the Rist mod$\mathrm{el}^{41)}$ in which the rate of chemical reaction was assumed to be infinite was also made and numerical results based on these analyses were compared with each other.

(1) Theory

(i) Analyses Based on the Method of Characteristics

When the concentration of inlet gas was time-invariant, the solution to the reduction rate was derived analytically in the case of the one interface model.42) When the concentration is time-variant, however, the reduction rate has to be analyzed numerically. Here, as partly reported previously, ${ }^{25)}$ the numerical calculation was carried out on the basis of the analysis of Yagi et al. ${ }^{\mathbf{4 3})}$; in order to examine the influence of dilution process due to an inert gas, Eq. (14) was used as a boundary condition.

Dimensionless fundamental equations based on the three interface model are also written as

$$
\begin{aligned}
& \partial \chi / \partial \theta+\partial \chi / \partial \eta=-\tilde{R}, \\
& \partial f / \partial \theta=\varphi \tilde{R}, \quad \ldots \ldots \ldots . .
\end{aligned}
$$

$$
\text { where, } \begin{array}{r}
\quad \tilde{R}=\tilde{R}\left(\chi, R_{\mathrm{i}}^{(\mathrm{m})}, R_{\mathrm{i}}^{(\mathrm{w})}, R_{\mathrm{i}}^{(\mathrm{Fe})}\right) \\
=-3\left(1-\varepsilon_{\mathrm{b}}\right) L n_{\mathrm{H}_{2}} /\left(4 \pi r_{\mathrm{o}}^{3} u_{\mathrm{m}} C_{\mathrm{H}_{2} \mathrm{~b}}\right), \ldots \\
\eta=z / L, \quad \theta=u_{\mathrm{m}} t /\left(\varepsilon_{\mathrm{b}} L\right), \quad \chi=C_{\mathrm{H}_{2}} / C_{\mathrm{H}_{2} \mathrm{~b}}, \\
\varphi=\varepsilon_{\mathrm{b}} C_{\mathrm{H}_{2} \mathrm{~b}} /\left[\left(1-\varepsilon_{\mathrm{b}}\right) \rho_{\mathrm{o}}^{(\mathrm{h})}\right], \\
R_{\mathrm{i}}^{(\mathrm{t})}=r_{\mathrm{i}}^{(\mathrm{t})} / r_{\mathrm{o}} . \quad(\mathrm{t}=\mathrm{m}, \mathrm{w}, \mathrm{Fe})
\end{array}
$$

The method of characteristics applied to Eqs. (30) and (31) yields

$$
\begin{array}{ll}
d \chi / d \eta=-\tilde{R} & (\theta=\eta+\text { const. }), \\
d f / d \theta=\varphi \tilde{R} & (\eta=\text { const. }) . . . .
\end{array}
$$

However, because Eq. (35) could not be calculated as it was, time variations of core radii were calculated along the characteristic line $\eta=$ const. on the basis of the three interface model, and then coupled with Eq. (34).

(ii) Approximate Analyses

If a fixed bed is assumed to be a stack of $M$ layers composed of $\mathcal{N}$ pellets per layer, then the mass-balance equation for each layer can be written under a quasi-steady state as

$$
C_{\mathrm{H}_{2} \mathrm{j}}=C_{\mathrm{H}_{2} \mathrm{j}-1}+n_{\mathrm{H}_{2}} \mathcal{N} / V_{\mathrm{T}} \quad(\mathrm{j}=2, \ldots, M), \ldots
$$

where $C_{\mathrm{H}_{2} \mathrm{j}}$ denotes the hydrogen concentration in the $\mathrm{j}$-th layer from the bottom of the bed, and $n_{\mathrm{H}_{2}}$ the reduction rate of a single pellet, which is evaluated by using the UCS models for one and three interfaces.

(2) Results and Discussion

(1) Comparison between the results calculated with the method of characteristics and calculated on the basis of the approximate analyses showed that distributions of hydrogen concentration differed a little from each other only at low flow rates and overall fractional-reductions were also much the same.

(2) Local fractional-reductions calculated by using the UCS models for one and three interfaces showed remarkable difference from each other except at the bottom of the bed, and therefore the overall fractional-reductions represented similar behavior. Calculated results based on the three interface model lay midway between calculated results based on the one interface model and on the Rist model (see Fig. 12).

(3) At low flow rates, overall fractional-reductions calculated by using the three interface model with $\kappa=$ 0 resulted in exceeding those based on the Rist model in the middle and the final stages, while those with $\kappa \geqq 0.5$ yielded fairly satisfactory results.

(4) The effect of dilution process due to an inert gas on the reduction rate was negligible, because the difference between the fractional-reductions calculated with and without Eq. (14) was found only in the initial stage at low flow-rates.

\section{Experimental Investigation ${ }^{25,44-46)}$}

Not only reduction curves and exit hydrogen flowrate but core radii in pellets and local fractional-reduction in beds reduced partially were measured and these data were compared with calculated results based on the UCS models and the Rist model. 


\section{(1) Experimental}

Packed beds of 0.5 to $6 \mathrm{~kg}$ Hamersley pellets $\left(\mathrm{SiO}_{2}\right.$ : $\left.5.1 \mathrm{wt} \%, \mathrm{Al}_{2} \mathrm{O}_{3}: 2.96 \mathrm{wt} \%, \varepsilon^{(\mathrm{h})}=0.21\right)$, the diameter of which ranged from 0.6 to $1.4 \mathrm{~cm}$, were reduced to the final stage in an $83 \mathrm{~mm}$ I.D. reactor over a temperature range 600 to $1000^{\circ} \mathrm{C}$ and a flow-rate range 1 to $45 \mathrm{~N} / / \mathrm{min}^{25,44)}$ An electric furnace for heating the reaction tube was divided into five parts, which were separately controlled in order to keep a fixed bed at a set temperature. Core radii in some of $4 \mathrm{~kg}$ pellets packed in a bed, which was reduced to the degree of $13,28,43,56,68$, or $84 \%$ under conditions of $800^{\circ} \mathrm{C}$, $7.1 \mathrm{~N} l / \mathrm{min}$, and $2 r_{\mathrm{o}}=1.1 \mathrm{~cm}$, were measured. $\left.{ }^{45}\right)$ Moreover fractional-reductions of these pellets were measured by the methods of oxidation and reduction, and two sorts of results were compared.46) Kinetic parameters in the three interface model were evaluated by single particle experiments [see Section II. 1.3. (2)].

(2) Results and Discussion

(i) Reduction Curves

(1) Calculated results based on the three interface model reproduced experimental data much better than those based on the Rist model or the one interface model (see Fig. 12).

(2) Calculated results based on the three interface model were in good agreement with experimental data over a temperature range 700 to $1000^{\circ} \mathrm{C}$ at $7.1 \mathrm{~N} l / \mathrm{min}$ and over a flow-rate range 1 to $45 \mathrm{~N} l / \mathrm{min}$ at $800^{\circ} \mathrm{C}$ for beds packed with $4 \mathrm{~kg}$ pellets, and over the amount of pellets 2 to $6 \mathrm{~kg}$ at $800^{\circ} \mathrm{C}$ and $7.1 \mathrm{~N} l$ $\min$.

(3) Measured reduction curves as well as calculated ones were in the same order of magnitude within this pellet-diameter range.

(4) The Rist model did not quantitatively reproduce experimental data, but predicted rather correct profile of the reduction curves for beds packed with a large amount of pellets and/or at low flowrates.

\section{(ii) Exit Hydrogen Flow-rate}

Figure 13 exemplifies exit hydrogen flow-rate. The calculated curve based on the three interface model reproduces experimental data better than the other two.

(iii) Core Radii in Partially Reduced Pellets

Every figure on axial variations of core radii at

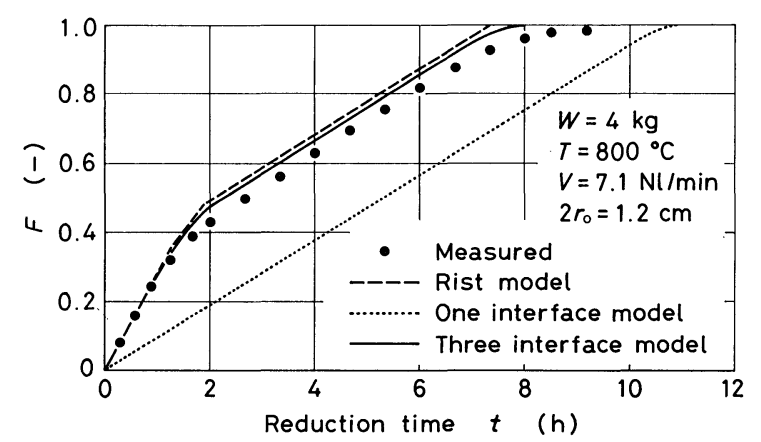

Fig. 12. Comparison of calculated reduction curves with experimental data. certain overall fractional-reductions (see Fig. 14) and on variations of core radii with overall fractionalreduction at certain heights in beds showed that, for the wüstite/iron interface, calculated curves based on the three interface model were in comparatively good agreement with the experimental data and for hematite/magnetite and magnetite/wüstite interfaces, roughly agreed with the data, which scattered in some extent.

(iv) Local Fractional-reduction

Figure 15 exemplifies axial distributions of local fractional-reduction measured by two methods of oxidation and reduction in comparison with the calculated curve based on the three interface model. For samples considered to be $f=1$, local fractionalreductions measured after $30 \mathrm{~h}$ oxidation yielded still

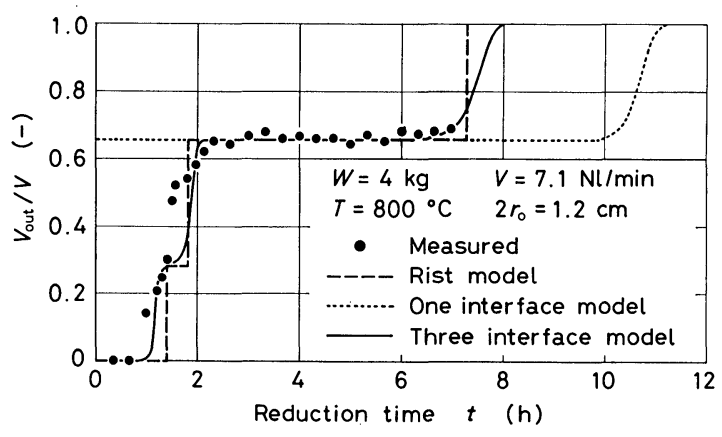

Fig. 13. Variation of exit hydrogen flow-rate $V_{\text {out }}$ with time.

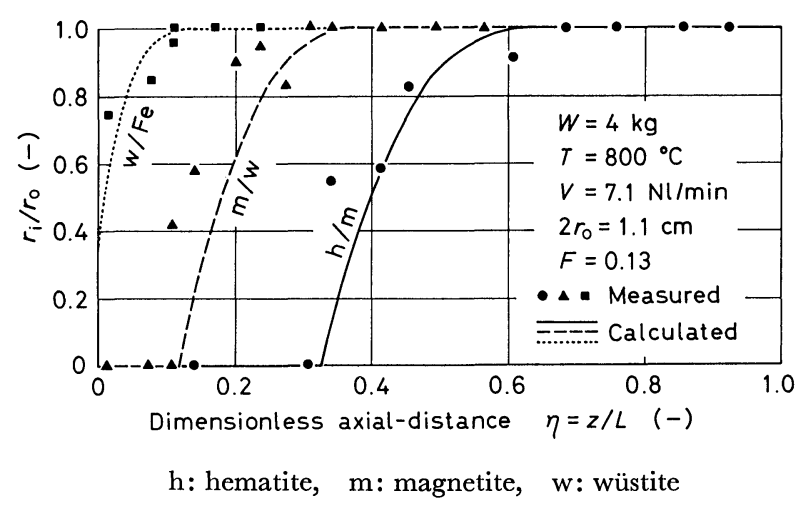

Fig. 14. Variation of core radii with axial distance. Three interface model.

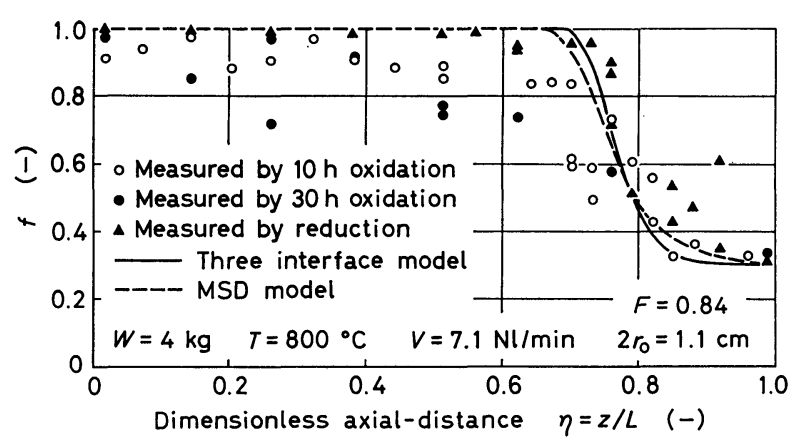

Fig. 15. Local fractional-reduction as a function of axial distance. 
unsatisfactory values, because reduced iron remained in the central part of pellets. Local fractional-reduction measured by the method of reduction was rather satisfactory and in relatively good agreement with the calculated one.

\section{Analyses Based on the Diffusional Models ${ }^{46,47)}$}

Reduction rate of fixed bed was also analyzed on the basis of the MSD models with and without the solid-state diffusion, and compared with the experimental results using Hamersley pellets ${ }^{46}$ ) or porous pure-hematite pellets and basic pellets prepared by hand-rolling. ${ }^{47)}$

\section{Theory}

When the MSD model was applied to fixed-bed analyses, pellets in a bed were considered to be reduced via various routes (see Fig. 1 in Ref. 46)), because of hydrogen-concentration variation in the bed. Basic equations and boundary conditions were given to each case and analytical relations were derived beforehand, and then coupled with the approximate analyses shown in Section III. 1.1.(1)-(ii) and numerical calculations were done. The MSD model with the solid-state diffusion was also applied to fixed-bed analyses.

\section{Experimental}

Hematite powders added with $7.4 \mathrm{wt} \%$ wood power of -35 mesh or with $1.67 \mathrm{wt} \% \mathrm{SiO}_{2}$ and $3.33 \mathrm{wt} \% \mathrm{CaO}$ were well mixed and pelletized, and then these green pellets were fired in $4 \mathrm{~h}$ at $1150^{\circ} \mathrm{C}$ and in $8 \mathrm{~h}$ at $1250^{\circ} \mathrm{G}$, respectively. The resultant pure-hematite and basic pellets had porosities of 38 and $18 \%$, diameters of 1.1 and $1.2 \mathrm{~cm}$, and the same weight $2.5 \mathrm{~g}$. Two sorts of pellets packed by $2 \mathrm{~kg}$ were reduced at $800^{\circ} \mathrm{C}$, $7.4 \mathrm{~N} l / \mathrm{min}$, and $1000^{\circ} \mathrm{C}, 42 \mathrm{Nl} / \mathrm{min}$, respectively. Cross sections of the pellets sampled from several heights in beds reduced partially were observed.

\section{Results and Discussion}

Experimental data of overall and local fractionalreduction (see Fig. 15) and exit hydrogen flow-rate were in good agreement with calculated results based on the MSD model and the three interface UCS model. However, microscopic observations of Hamersley and pure-hematite pellets reduced partially in beds revealed that phases of hematite, magnetite, wüstite, and iron coexisted and reaction zones were formed. Figure 16 gives comparison between measured and calculated results for the basic pellet. In the case of single particle experiments, such a pellet showed extremely low reduction-rate in the final stage, but not so much in this experiment. Wüstite particle radius in the MSD model in consideration of the solid-state diffusion was determined as $r_{\mathrm{c}}=5 \mu \mathrm{m}$ from microscopic observation. If the radius is much larger, however, fairly low reduction-rate in the final stage is estimated.

\section{Concluding Remarks}

Single particles and fixed beds of various iron oxide pellets were reduced with hydrogen over a wide range of flow rate and a temperature range 600 to $1000^{\circ} \mathrm{C}$, and their reduction rates were analyzed by using the

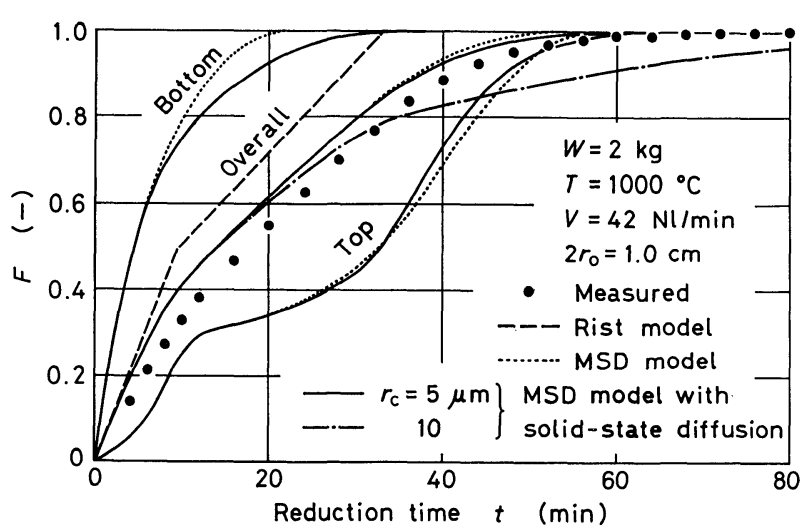

Fig. 16. Comparison between calculated reduction curves and experimental data.

UCS models for one and three interfaces in consideration of dilution processes due to inert and product gases. Measured and calculated results of reduction curves and core radii showed satisfactory agreements in a macroscopic sense. The other analyses based on the diffusional models were also done and the calculated results reproduced cross-sectional view fairly well in a microscopic sense and reduction curves precisely up to the final stage. In order to analyze the rate of reduction of iron oxide pellets in various reactors more precisely up to the final stage, further developments of the above-mentioned analyses are desired.

\section{Nomenclature}

$C_{\mathrm{H}_{2}}$ : molar concentration of hydrogen $\left(\mathrm{mol} \mathrm{H} \mathrm{H}_{2} /\right.$ $\mathrm{cm}^{3}$ )

$C_{0}^{*}$ : concentration of oxygen dissolved in metallized iron $\left(\mathrm{mol} \mathrm{O} / \mathrm{cm}^{3}\right)$

$D:$ dispersion coefficient $\left(\mathrm{cm}^{2} / \mathrm{s}\right)$

$D_{\mathrm{e}}$ : intra-particle effective diffusivity $\left(\mathrm{cm}^{2} / \mathrm{s}\right)$

$D_{K}:$ Knudsen diffusivity $\left(\mathrm{cm}^{2} / \mathrm{s}\right)$

$D_{\mathrm{O}}$ : diffusivity of oxygen dissolved in metallized iron $\left(\mathrm{cm}^{2} / \mathrm{s}\right)$

$D_{X Y}$ : binary bulk diffusivity for a system $X-Y\left(\mathrm{~cm}^{2} /\right.$ s)

$d_{0}:$ oxygen content of wüstite $\left(\mathrm{mol} \mathrm{O} / \mathrm{cm}^{3}\right)$

$d_{R}$ : diameter of a reactor $(\mathrm{cm})$

$F, f:$ overall and local fractional-reduction

$K$ : equilibrium constant

$k_{\mathrm{c}}$ : rate constant of chemical reaction $(\mathrm{cm} / \mathrm{s})$

$k_{\mathrm{f}}$ : mass-transfer coefficient in a gas film $(\mathrm{cm} / \mathrm{s})$

$k_{v}^{(j)}$ : reaction rate constant based on volume $\left[\mathrm{cm}^{3} /\right.$ $(\mathrm{mol} \mathrm{H} \cdot \mathrm{s})]$

$L$ : length of a reactor or a fixed bed $(\mathrm{cm})$

$n_{\mathrm{H}_{2}}$ : reaction rate or transfer rate of hydrogen $(\mathrm{mol}$ $\mathrm{H}_{2} / \mathrm{s}$ )

$r:$ radial distance in a pellet $(\mathrm{cm})$

$r_{\mathrm{c}}$ : radius of constituent (wüstite) particles $(\mathrm{cm}$, unless otherwise noted)

$r_{\mathrm{j}}:$ radii of the boundaries in the MSD models $(\mathrm{cm})$

T: reduction temperature $\left({ }^{\circ} \mathrm{C}\right)$

$t:$ reduction time (s, unless otherwise noted)

$u_{\mathrm{m}}:$ cross sectional mean velocity in a tube $(\mathrm{cm} / \mathrm{s})$

$V$ : gas flow rate at the normal state $(\mathrm{N} l / \mathrm{min})$ 
$V_{\mathrm{M}}:$ molar volume $\left(\mathrm{cm}^{3} / \mathrm{mol}\right)$

$V_{\mathrm{T}}$ : gas flow rate $\left(\mathrm{cm}^{3} / \mathrm{s}\right)$

$W:$ amount of pellets packed in a bed $(\mathrm{kg})$

$x$ : mole fraction

$z:$ axial distance in a fixed bed $(\mathrm{cm})$

$\varepsilon:$ porosity of a pellet

$\varepsilon_{\mathrm{b}}$ : void fraction of a fixed bed

$\kappa$ : coefficient indicating to what extent the resistance due to the rate of gas flow contributes

$\rho_{0}$ : apparent molar-density of oxygen $\left(\mathrm{mol} \mathrm{O} / \mathrm{cm}^{3}{ }_{-}\right.$ pellet)

\section{Subscripts and Others}

a, b, e, i, o: quantities associated with average, bulk phase, equilibrium, reaction interface, and outer surface of a pellet

$c, d, f:$ quantities associated with chemical reaction process, intra-particle diffusion process, and diffusion process in gas film

h, m, w: abbreviations for hematite, magnetite, and wüstite

\section{Acknowledgements}

The authors are grateful to Nippon Steel Corp. and Kobe Steel, Ltd. for supplying hematite pellets and to co-workers (Mr. E. Yamamura of Nakayama Steel Works Co., Ltd., Mr. Y. Minamide of the Min. of Finance, Mr. K. Nakajima of Sumitomo Metal Ind., Ltd., Mr. M. Naitō of Graduate School, Osaka University, Mr. H. Kamiya of Honda Mortors Co., Ltd. and others) for their help.

\section{REFERENCES}

1) A. Moriyama, J. Yagi and I. Muchi: J. Japan Inst. Metals, 29 (1965), 528; Trans. ISIJ, 7 (1967), 271.

2) R. H. Spitzer, F.S. Manning and W. O. Philbrook: Trans. Met. Soc. AIME, 236 (1966), 726.

3) T. Yagi and Y. Ono: Trans. ISIJ, 8 (1968), 377.

4) R. Takahashi, J. Yagi and Y. Omori: Bull. Res. Inst. Min. Dres. Met., Tohoku Univ., 26 (1970), 83.

5) R. Takahashi, J. Yagi and Y. Omori: Tetsu-to-Hagané, 57 (1971), 1597; Sci. Rep. Res. Inst. Tohoku Univ., 23 (1971), 9.

6) H. W. St. Clair: Trans. Met. Soc. AIME, 233 (1965), 1145.

7) Y. Hara, M. Tsuchiya and S. Kondo: Tetsu-to-Hagané, 55 (1969), 1297; Trans. ISIJ, 12 (1972), 223.

8) M. Ohmi and T. Usui: Tetsu-to-Hagané, 59 (1973), 1888; Trans. ISIJ, 16 (1976), 77.

9) T. Murayama, Y. Ono and Y. Kawai: Tetsu-to-Hagané, 63 (1977), 1099; Trans. ISIJ, 18 (1978), 579.

10) R. H. Spitzer, F. S. Manning and W. O. Philbrook: Trans. Met. Soc. AIME, 236 (1966), 1715.

11) Y. Hara, M. Tsuchiya and S. Kondo: Tetsu-to-Hagané, 60 (1974), 1261.

12) T. Murayama, Y. Ono and Y. Kawai: Tetsu-to-Hagané, 63 (1977), 1229; Trans. ISIJ, 18 (1978), 776.

13) M. Ishida and C. Y. Wen: AIChEJ., 14 (1968), 311.

14) J. Szekely and J. W. Evans: Met. Trans., 2 (1971), 1691.

15) Y. Hara: Tetsu-to-Hagané, 57 (1971), 1441; Trans. ISIJ, 12 (1972), 358.

16) D. Papanastassiou and G. Bitsianes: Met. Trans., 4 (1973), 477.
17) J. M. Ausman and G. C. Watson: Chem. Eng. Sci., 17 (1962), 323.

18) J. H. Bowen and G. K. Cheng: Chem. Eng. Sci. 24 (1969), 1829.

19) A. Calvelo and R. E. Cunningham: J. Catalysis, 17 (1970), 1 .

20) M. Ishida and C. Y. Wen: Chem. Eng. Sci., 26 (1971), 1031.

21) R. H. Tien and E. T. Turkdogan: Met. Trans., 3 (1972), 2039.

22) S. P. Trushenski, Kun $\mathrm{Li}$ and W. O. Philbrook: Met. Trans., 5 (1974), 1149.

23) Y. Ono and T. Joko: Tetsu-to-Hagané, 63 (1977), 1785.

24) M. Ohmi, T. Usui, M. Naitō and T. Kaida: Tetsu-toHagané, 63 (1977), S450.

25) M. Ohmi, T. Usui, Y. Minamide and M. Naitō: Proc. 3rd Int. Iron Steel Congress, April 1978, Chicago, ASM, Ohio, (1979), 472.

26) R. Takahashi, J. Yagi and Y. Omori: Bull. Res. Inst. Min. Dres. Met., Tohoku Univ., 30 (1974), 109.

27) M. Ohmi, T. Usui, Y. Minamide and M. Naitō: Tetsu-toHagané, 63 (1977), S451.

28) M. Ohmi, T. Usui, M. Naitō and T. Satsuma: Tetsu-toHagané, 64 (1978), S77.

29) M. Tokuda, H. Yoshikoshi and M. Ohtani: Tetsu-toHagané, 56 (1970), 1899; Trans. ISIJ, 13 (1973), 350.

30) O. Levenspiel and K. B. Bischoff: Adv. Chem. Eng., 4 (1963), 95.

31) M. Ohmi, T. Usui and K. Nakajima: Tetsu-to-Hagané, 61 (1975), S368.

32) H. K. Kohl and B. Marincek: Helv. Chem. Acta, 48 (1965), 1857.

33) M. Ohmi, T. Usui and K. Nakajima: Tetsu-to-Hagané, 66 (1980), 449; Trans. ISIJ, 22 (1982), 30.

34) M. Ohmi, T. Usui and E. Yamamura: Tetsu-to-Hagané, 66 (1980), S54; Trans. ISIJ, 20 (1980), B426.

35) M. Ohmi, M. Naitō and T. Usui: Tetsu-to-Hagané, 65 (1979), S6; to be published in Tetsu-to-Hagané, 68 (1982).

36) M. Ohmi, M. Naitō and T. Usui: Tetsu-to-Hagané, 66 (1980), S2; Trans. ISIJ, 20 (1980), B350.

37) H. K. Kohl and H.J. Engell: Arch. Eisenhüttenw., 34 (1963), 411.

38) L. von Bogdandy and H.-J. Engell: Die Reduktion der Eisenerze, Springer-Verlag, Berlin/Heidelberg and Verlag Stahleisen m.b. H., Düsseldorf, (1967), 127.

39) M. Ohmi, M. Naitō and T. Usui: Tetsu-to-Hagané, 66 (1980), S55 and S605; Trans. ISIJ, 21 (1981), B3.

40) M. Ohmi, T. Usui, M. Naitō and K. Takagi: Tetsu-toHagané, 64 (1978), S462.

41) A. Rist and G. Bonnivard: Rev. Mét., 60 (1963), 23.

42) A. Moriyama: Kagaku Kögaku (Chem. Eng. Japan), 34 (1970), 1308; Trans. ISIJ, 11 (1971), 176.

43) J. Yagi, R. Takahashi and Y. Omori: Tetsu-to-Hagané, 57 (1971), 1453; Sci. Rep. Res. Inst., Tohoku Univ., A23 (1971), 31.

44) M. Ohmi, T. Usui, T. Masuda and H. Kawamura: Tetsuto-Hagané, 64 (1978), S463.

45) M. Ohmi, T. Usui, M. Naitō and H. Kamiya: Tetsu-toHagané, 65 (1979), S616.

46) M. Ohmi, T. Usui, H. Kamiya and Z. Fukuda: Tetsu-toHagané, 66 (1980), S607; Trans. ISIJ, 21 (1981), B5.

47) M. Ohmi, T. Usui, M. Naitō and H. Kamiya: Preprint of the 87th Japan Inst. Metals Meeting, (1980), 276.

48) M. Ohmi, T. Usui, M. Naitö and Y. Minamide: Tetsuto-Hagané, 67 (1981), 1943. 